\title{
Modeling of UV Disinfection Irradiation Installations Using Computer Graphics Programs
}

\author{
Tatiana Meshkova ${ }^{[0000-0003-1008-2161]}$ and Vladimir Budak [0000-0003-4750-0160] \\ National Research University "Moscow Power Engineering Institute", Krasnokazarmen- \\ naya 14 , Moscow, 111250 Russia \\ tvmesh@mail.ru, budakvp@gmail.com
}

\begin{abstract}
In connection with the appearance and spread of COVID-19, lighting equipment manufacturers have prepared product lines and marketing programs to promote irradiators for air disinfection for domestic and industrial needs. In this regard, the CIE issued an official request for the use of ultraviolet radiation to fight the spread of COVID-19. Nevertheless, the penetration force of ultraviolet rays is small. The action of rays is limited only to the surface of the irradiated object, and the method of calculating and simulating irradiators is based on obtaining normalized values of irradiation on the surface. However, the main goal of designing bactericidal systems is to distribute UV radiation uniformly in all directions of engineering designs, regardless of their type. However, now, there is no computer graphics program allows you to get the values of normalized values at each point in space to check the effectiveness of the bactericidal system. This article presents a new method for solving the problem of modeling irradiation installations with the ability to analyze the normalized values at each point of the volume of air being treated.
\end{abstract}

Keywords: UV-Radiation, Room Disinfection, Irradiation, Protection from COVID-19.

\section{Introduction}

In connection with the appearance and spread of COVID-19, lighting equipment manufacturers have prepared product lines and marketing programs to promote irradiators for air disinfection for domestic and industrial needs. In this regard, the CIE issued an official request for the use of ultraviolet radiation to fight the spread of COVID-19. [1]

According to the design, UV bactericidal irradiators can be divided into two groups: open - type irradiators or closed-type recirculators. The main feature of bactericidal irradiators of the open type is that the flow of ultraviolet radiation from it spreads throughout the space where the light from the bactericidal lamp falls. This is the most effective way to disinfect both the air and surfaces of the room, and even objects in the room. Nevertheless, the penetration force of ultraviolet rays is small. Even a thin layer

Copyright c 2020 for this paper by its authors. Use permitted under Creative Commons License Attribution 4.0 International (CC BY 4.0). 


\section{T. Meshkova, V. Budak}

of glass is enough to prevent their passage. The action of the rays is limited only by the surface of the irradiated object. In other words, UV radiation is effective if microorganisms and dust particles are located in the same layer, but in a multi-layer arrangement, the phenomenon of shielding occurs: the upper layers protect the lower layers.

The main goal of designing bactericidal systems is the uniform distribution of UV radiation in all directions of engineering structures, regardless of their type. For example, there are bactericidal systems with built-in fans to improve air mixing, which significantly increases the overall efficiency of the systems. However, now there is no computer graphics program allows you to get the values of normalized values at each point in space to verify the effectiveness of the bactericidal system.

The method of calculating and modeling irradiators is based on obtaining normalized values of irradiation on the surface, while for the above reasons, for high-quality disinfection, it is necessary to calculate the irradiation of the treated air in volume.

The basis of both computer graphics and calculation of the irradiation system in lighting engineering is the equation of global illumination (GI), obtained in 1986 by $\mathrm{J}$. Kajia [2]

By modeling GI equation, we get a spatial-angular distribution of brightness, i.e. visualization of $3 \mathrm{M}$ scenes. The equation is an integral equation of the second kind, and, accordingly, it does not have an analytical solution in general (except for some special cases that can be applied to evaluate a particular numerical method. Currently, there are a number of numerical methods for solving GI equation, but all of them have a number of assumptions that ultimately affect the reliability of the calculation. The most common computer programs for designing lighting installations, such as DIALux [3] and Relux [4], are based on the method of radiosity and, accordingly, do not get the ability to calculate the spatial-angular distribution of brightness.

In addition, the work of bactericidal irradiators, sufficient for surface disinfection, is ineffective in the case of air disinfection. Although it is worth noting that properly designed bactericidal systems are able to process both air and surfaces simultaneously. You can improve system performance by improving the overall reflectivity of the internal surfaces of air ducts or supply units. This results in the reflection of UV radiation into the irradiation zone and an increase in the UV dose.

This article presents a new method for solving the problem of simulating irradiation installations with the possibility of analyzing the normalized values at each point of the volume of air being treated.

\section{Simulation of Irradiation Facilities}

Currently, Russia has General recommendations and rules for the use of UV radiation for disinfection of premises. The main of them are the following:

* Manual P 3.1.683-98 "Use of ultraviolet, bactericidal radiation for disinfection of air and surfaces in premises";

* Guidelines MU 2.3.975-00 "application of ultraviolet bactericidal radiation for air disinfection of premises of organizations of the food industry, public catering and food trade"; 
* Guidelines for the use of bactericidal lamps for disinfection of air and surfaces in premises. Order no. 11-16 / 03-06 February 28, 1995;

* Resolution of the Chief state sanitary doctor of the Russian Federation of November 18, 2013 N 63 Moscow "on approval of sanitary and epidemiological rules SP 3.1.2.3117-13 "Prevention of influenza and other acute respiratory viral infections".

The main restrictions on the use of irradiation installations for disinfection purposes can be presented in the Table 1 .

Table 1. Restrictions on the use of UV radiation to disinfect the premises

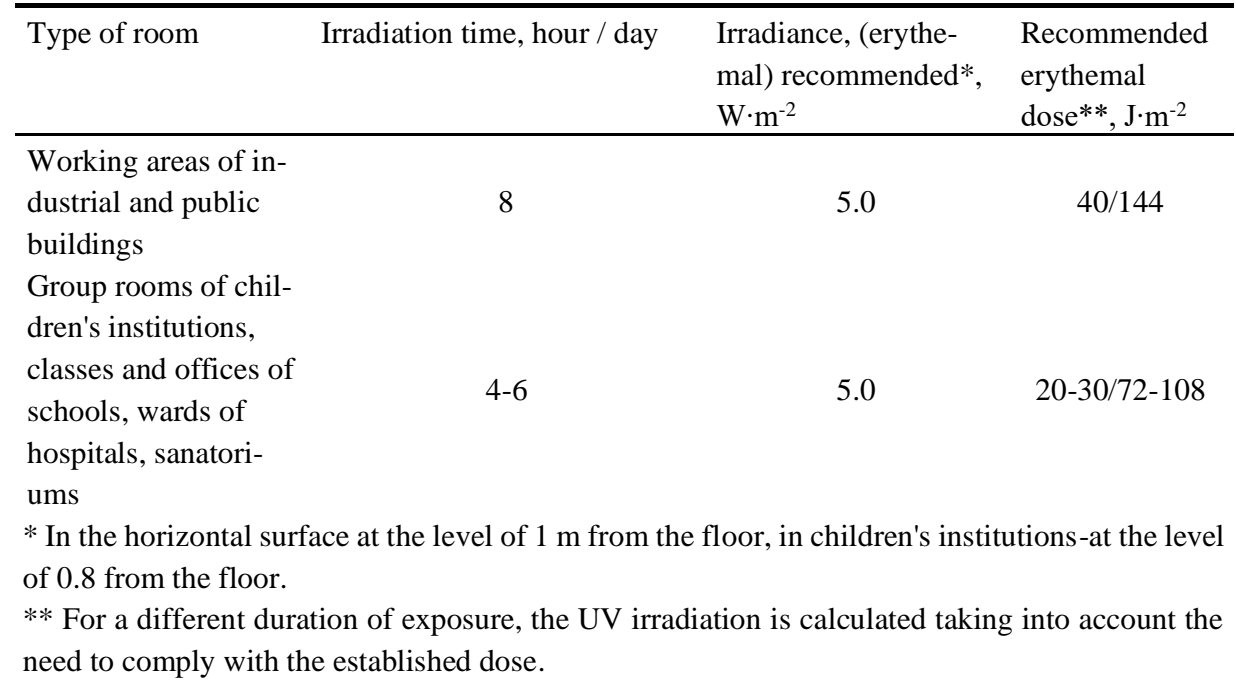

The normalized fluence values are used for modeling the irradiation system and developing the irradiator itself (Table. 1). Usually, the fluence or surface radiation dose values for some viruses are determined at a wavelength of $254 \mathrm{Nm}$, and the inactivation efficiency is determined by 4 orders of magnitude $(99.99 \%)$.

The bactericidal dose (fluence) $\mathrm{D}$ is determined by the expression

$$
D=\iint E(\lambda, t) S(\lambda) d \lambda d t,
$$

where $E(\lambda, t)$ - time dependence of the spectral density of bactericidal irradiance. The value of $\mathrm{D}$, required for a tenfold reduction №, depends on the type of microorganism and for many bacteria and viruses is $2-20 \mathrm{~mJ} / \mathrm{cm}^{2}$.

Note that irradiance, as well as illuminance. - is a parameter determined relative to the surface of the room.

The practical programs DIALux and Relux, commonly used in the design of lighting installations, simulate the distribution of light in a diffuse approximation. The algorithm for calculating these programs uses the radiation equation [6], which is solved by the finite element method and is a consequence of the global illumination equation [7] in the diffuse approximation (2). 


$$
M(\mathrm{r})=M_{0}(\mathrm{r})+\frac{\sigma(\mathrm{r})}{\pi} \int_{\Sigma} M\left(\mathrm{r}^{\prime}\right) F\left(\mathrm{r}, \mathrm{r}^{\prime}\right) \Theta\left(\mathrm{r}, \mathrm{r}^{\prime}\right) d^{2} \mathrm{r}^{\prime}
$$

where $M(r)$ - luminous exitance at a point on a surface $r, M_{0}(r)$ - first luminous exitance at a point on a surface $r$ directly from light sources in the approximation of a single reflection, $\Theta\left(\mathbf{r}, \mathbf{r}^{\prime}\right)$ - the visibility function of a point $r$ from point $\mathbf{r}^{\prime}$ ( 1 if visible и 0 if not), $F\left(\mathbf{r}, \mathbf{r}^{\prime}\right)$ - elementary form factor [8], $\sigma(\mathbf{r})$ - reflection coefficient.

As part of this work, local estimation algorithms were applied to the solution of the global illumination equation [7]:

$$
\begin{gathered}
L(r, \hat{l})=L_{0}(r, \hat{l})+\frac{1}{\pi} \int L\left(r^{\prime}, \hat{l}^{\prime}\right) \sigma\left(r ; \hat{l}^{\prime}, \hat{l}\right)\left|G\left(\widehat{N}, \hat{l}^{\prime}\right)\right| d \hat{l}^{\prime}, \\
L(r, \hat{l})=L_{0}(r, \hat{l})+\frac{1}{N} \sum_{i=1}^{N}\left(\frac{1}{\pi} \frac{L_{0}\left(r_{1 i}, \hat{l}_{1 i}\right)}{p_{1}\left(r_{1 i}, \hat{l}_{1 i}\right)} \frac{\sigma\left(r ; \hat{l}_{1 i}, \hat{l}\right) G\left(r_{1}, r\right)}{p_{2}\left(r_{1 i}, \hat{l}_{1 i} \rightarrow r, \hat{l}\right)}+\right. \\
\left.+\frac{1}{\pi^{2}} \frac{L_{0}\left(r_{1 i}, \hat{l}_{1 i}\right)}{p_{1}\left(r_{1 i}, \hat{l}_{1 i}\right)} \frac{\sigma\left(r_{2 i}, \hat{l}_{1 i}, \hat{l}_{2 i}\right) G\left(r_{1 i}, r_{2 i}\right)}{p_{2}\left(r_{1 i}, \hat{l}_{1 i} \rightarrow r_{2 i}, \hat{l}_{2 i}\right)} \frac{\sigma\left(r ; \hat{l}_{2 i}, \hat{l}\right) G\left(r_{2 i}, r\right)}{p_{2}\left(r_{2 i}, \hat{l}_{2 i} \rightarrow r, \hat{l}\right)}+\cdots\right) .
\end{gathered}
$$

Using these transformations, you can get the luminance value at each point in space. However, in our case, fluence rate is important for estimating UV radiation at each point in the volume of air being treated, so we can use the local estimation method to solve the global illumination equation, as follows:

$$
E(r, \hat{l})=E_{0}(r, \hat{l})+\frac{1}{\pi} \int E\left(r^{\prime}, \hat{l}^{\prime}\right) \sigma\left(r ; \hat{l}^{\prime}, \hat{l}\right) G\left(r^{\prime}, r\right) d^{3} r^{\prime}
$$

Especially when modeling irradiation installations, it is necessary to pay attention to the fact that the reflection and transmission of substances in the UV field of the spectrum differ from those existing in the visible field. A characteristic peculiarity here is a decrease in transparency (an increase in the absorption coefficient) of most bodies that are transparent in the visible field. For example, ordinary glass is opaque at $\lambda<320 \mathrm{~nm}$, and boron-silicate UV transparent quartz glass, quartz, etc. Moreover, the air is opaque at $\lambda<200-190 \mathrm{~nm}$, primarily due to the absorption of oxygen and water vapor. For high-quality disinfection of the room using UV irradiation, it is necessary to consider this.

Since the method is designed to calculate light values, the conversion coefficients can be used to convert the resulting value to energy, photon, or conversely.

Coefficient of conversion of energy values to light values, $1 \mathrm{~m} / \mathrm{W}$ :

$$
K=\frac{K_{m} \int_{400}^{700} \varphi(\lambda) \cdot V(\lambda) \cdot d \lambda}{\int_{400}^{700} \varphi(\lambda) \cdot d \lambda}
$$

Coefficient of conversion of energy values to photons, mol/J:

$$
K=\frac{K_{m} \int_{400}^{700} \varphi(\lambda) \cdot \frac{\lambda}{h \cdot c \cdot N_{A}} \cdot d \lambda}{\int_{400}^{700} \varphi(\lambda) \cdot d \lambda},
$$

Conversion coefficient of light values to photons, $\mathrm{mol} / \mathrm{s} \cdot \operatorname{lm}(8)$. 


$$
K=\frac{K_{m} \int_{400}^{700} \varphi(\lambda) \cdot \frac{\lambda}{h \cdot c \cdot N_{A}} \cdot d \lambda}{\int_{400}^{700} \varphi(\lambda) \cdot V(\lambda) \cdot d \lambda}
$$

where $\mathrm{h}=6,62610^{-34} \mathrm{~J} \cdot \mathrm{Hz}^{-1}-$ Planck constant; $\mathrm{c}=3 \cdot 1017 \mathrm{~nm} / \mathrm{s}-$ the speed of light in vacuum; $\mathrm{N}_{\mathrm{A}}=6,022 \cdot 1023 \mathrm{~mol}^{-1} ; \mathrm{Km}-$ the multiplier for day vision is equal to 683 $\mathrm{lm} / \mathrm{W} ; \mathrm{V}(\lambda)$ - spectral luminous efficiency.

Thus, it becomes possible to estimate the radiation dose in volume when designing irradiation installations.

\section{Irradiation Installations}

Ultraviolet radiation is known to have a wide range of effects on microorganisms, including bacteria, viruses, spores and fungi.

UV radiation (UVR) is electromagnetic radiation that occupies the range between visible and roentgen radiation, with a wavelength of $\lambda$ from 400 to $10 \mathrm{~nm}$. UVR is divided into near $(\lambda=400-200 \mathrm{~nm})$ and far, or vacuum $1,(\lambda=200-10 \mathrm{~nm})$ UVR. According to the biological effect, there are three sections of the near-UV spectrum: UVA- $\lambda=315-400 \mathrm{~nm}$, UV-B-280-315 nm, and UV $-C-200-280 \mathrm{~nm}$. The biological effect of UVR on $\lambda=315-390 \mathrm{~nm}$ is mainly tanning. UVR at $\lambda=280-400 \mathrm{~nm}$ in certain doses is useful for the human body, animals and birds, having a so-called "vital" effect. UVR in the UV-B range (280-315 $\mathrm{nm}$ ) has an antimicrobial effect, and UVR in the UV-C range $(200-315 \mathrm{~nm})$ is able to inactivate microorganisms. UVR at $\lambda=205-315 \mathrm{~nm}$ always produces a bactericidal effect, which consists in the absorption of UV photons by DNA and RNA molecules. UV-C is often called bactericidal because of its effectiveness against bacteria and viruses. [9]

Indoor air disinfection can be achieved by various methods, the most widely used of which disinfection with bactericidal ultraviolet radiation (UVR) is using bactericidal lamps. If the ventilation and air conditioning system has design or operational deficiencies, it can itself be a source of infection. Such irradiators are divided into two groups. The first group includes the UV irradiators of open type, and the ultraviolet radiation directly disinfects the air inside the room. Such irradiators are used in the absence of people. The second group is a type of recirculation, in which ultraviolet radiation is concentrated inside the chamber, through which a fan pumps the internal air, and the purified air is injected back into the room. Bactericidal irradiators are integrated into systems with forced ventilation and dust filters and as such belong to the second group [9]. Open-type irradiation requires periodic rest of the room to be sanitized, or its use during non-working hours (most often at night) [10].

Ceiling recirculators can be used for decontamination of premises. Ceiling recirculators with germicidal lamps located perpendicular to the airflow have better technical, microbiological and economic indicators than wall recirculators with germicidal lamps located parallel to the airflow. For indoor air disinfection in the presence of people it opens up prospects for creating more efficient industrial models of recirculators [11].

Traditionally produced in Russia, open irradiators are focused on the disinfection of air and surfaces with the sanitary indicator microorganism Staphylococcus aureus. To achieve a $99.9 \%$ degree of disinfection, therefore, the sanitary indicator microorganism 
requires a dose of $6.9 \mathrm{MJ} / \mathrm{cm}^{2}$ bactericidal UV irradiation. To achieve the same degree of disinfection ( $99.9 \%$ ) for other microorganisms, significantly higher doses of UV radiation may be required [9].

However, it should be noted that the selection and effective use of UV recirculators is a separate technological task. A simple example is a doctor's office, the volume of the room is $50 \mathrm{~m}^{3}$, a recirculator with a capacity of $50 \mathrm{~m}^{3} / \mathrm{h}$ is installed, but not earlier than an hour later, you can process all the air in the office, while in real life, 3-4 patients can visit the office during this time. The multiplicity of air exchange with purified air is a determining factor in achieving the necessary degree of disinfection [9]. Thus, the main task facing developers of a powerful UV radiation source is to increase efficiency in a given spectral range and increase it's lifetime. The first problem is solved by selecting the optimal filling and maintaining a certain thermal mode of operation of the source; the second depends on the materials used in the source: their purity, heat resistance, reliability, etc. At the first stage, the type and discharge conditions of the developed radiation sources are selected, then the optimal ratio of the source parameters is selected depending on the requirements and operating conditions [12, 13].

Therefore, when modeling an effective bactericidal system, one of the important factors is also the correct calculation of air exchange in the volume to be cleaned.

\section{Conclusion}

In modern Domestic literature and regulatory documents on the use of bactericidal radiation, some simplifications are allowed, which in some cases lead to significant errors in the calculations of installations.

In an unmixed medium with a very high UV absorption coefficient (when bactericidal radiation is absorbed in the surface layer of the medium), the surface components of the medium (including bacteria) will receive "excess" radiation, and the components in the depth of the layer will receive a dose close to zero.

Unirradiated (optically removed from the radiation source) surfaces eventually become infected and infect the treated masses.

At the same time, the design of irradiation plants is mainly focused on the implementation of standard values on the surface, while disinfection is important in the volume of air. Moreover, modern computer graphics programs do not allow you to calculate the necessary parameters at each point in space.

However, due to the application of the local estimation method to the solution of the global illumination equation, it became possible to obtain and analyze photon fluence rate when modeling bactericidal systems.

It is also necessary to note the important role of air exchange in the cleaned volume when modeling an effective irradiation system.

A similar approach can also be used to estimate greenhouse irradiation within the plant layer. 
Modeling of UV Disinfection Irradiation Installations Using Computer Graphics Programs 7

\section{References}

1. https://1-e-journal.com/news/novoe-ofitsialnoe-zayavlenie-mko/

2. Kajiya J.T. The rendering equation // Computer Graphics (Proc. SIGGRAPH'86), 1986. V. 20, No. 4, pp. 143-150.

3. www.dialux.de

4. www.relux.biz

5. Cindy G., Kenneth E., Torrance, Donald P. Greenberg and B. Battaile Modeling the interaction of light between diffuse surfaces // Computer Graphics, 1984. V. 18, No. 3.

6. Kajiya J. T. The rendering equation // Computer Graphics (Proc. SIGGRAPH'86), 1986. V. 20, No. 4, pp. 143-150.

7. Budak V., Zheltov V. Local Monte Carlo estimation methods in the solution of global illumination equation // Journal of WSCG, 2014. p. 25.

8. Spravochnaya kniga po svetotekhnike: spravochnoe izdanie // pod red. YU. B. Ajzenberga. 4-e izd., pererab. - M. : [B. I.], 2019. P. 892.

9. Alferova L. K., Ovchukova S. A. Sposoby uvelicheniya funkcional'noj effektivnosti UF obluchatel'nyh ustanovok //Svetotekhnika, 2000. № 1, P. 15-18.

10. Vasserman A.L., Yuzbashev V.G. An Engineering Method for Calculating Enclosed Germicidal Irradiators in the Disinfection of Indoor Air // Light and Engineering, 2008. V. 16, No. 3, pp. 78-82.

11. Vasserman A. L., YUzbashev V. G. Mikrobiologicheskie issledovaniya baktericidnoj effektivnosti ul'trafioletovogo potolochnogo recirkulyatora // Svetotekhnika, 2005. № 4, P. 36-39.

12. Demkin V. K., Loktev V. G., Troshkin S. V. O razlozhenii organicheskih veshchestv opticheskim izlucheniem shirokogo spektral'nogo diapazona // Svetotekhnika, 2000. № 3, P. 25 26.

13. Kostyuchenko S. V., Kudryavcev N. N., Kuz'menko M. E., Pecherkin V. YA. Issledovanie zazhiganiya amal'gamnoj baktericidnoj lampy nizkogo davleniya // Svetotekhnika, 2000. № 3, P. 30-32. 